\title{
An Interventional Study to See the Effect of Acute Intake of Caffeine on Reaction Time in Young Healthy Adults Consuming Moderate Amount of Caffeine for Six Months
}

\author{
Dr. Pagar A. B. ${ }^{1}$, Dr. Raut S. E. ${ }^{2}$ \\ ${ }^{I}$ (Department Of Physiology, BVDU Medical College, Sangli, Bharatividyapeeth Deemed University, India) \\ ${ }_{2}^{2}$ (Department Of Physiology, Govt. Medical College, Miraj, MUHS Nashik, India)
}

\begin{abstract}
Context: Caffeine produces positive effects on mood and performance. However, tolerance may develop following habitual use. Simple reaction time is an important parameter to judge the alertness and visual motor performance as it represents the integrity of sensory, motor and coordination system of the body. So, present study is carried out to see the effect of caffeine on alertness \& performance in non-caffeinated state \& after regular long term moderate caffeine consumption in young healthy adults.

Aims: To see the reaction time in healthy young subjects who were not regular caffeine consumers, before and after acute dose of caffeine and in same subjects after six months of regular moderate daily caffeine consumption.

Methods and Material: The study was conducted on 30 male and 30 female healthy subjects reporting a caffeine intake equal to less than two servings i.e. 200mg. in age group 20 to 25 years. Thorough general and systemic examination was carried out. Reaction time was recorded before and 30 minutes after intake of about $250 \mathrm{mg}$ of caffeine. The same subjects were asked to drink 2-5 cups of coffee per day for next six months. After six months, subjects were assessed before and 30 minutes after intake of caffeine.

Statistical analysis used: Student's Paired t test was applied to compare the RT before and after intake of caffeine. Unpaired t test was applied to compare the audio-visual RT between male and female subjects. A $P$ value $<0.05$ is considered as significant.

Results: The auditory reaction times are faster than visual reaction times. Males reacted faster than females though not statistically significant. Reaction Time to Auditory and Visual stimuli reduced very significantly after intake of caffeine in both Males and Females in non-habitual caffeine consumption state. It decreases significantly after acute dose of caffeine in same subjects after regular long term consumption of moderate caffeine as well, though the decrease is less than that in non-habitual state.

Conclusions: The caffeine was effective in improving audio-visual reaction time in both the states that is non habitual caffeine consumption state and in the same subjects after regular long term consumption of moderate caffeine
\end{abstract}

Keywords: audio-visual reaction time, Caffeine, habitual caffeine consumption, Reaction time

\section{Introduction}

A cup of coffee in the morning to start a day is important for most of the people. Acute caffeine intake improves self-reported alertness and visual motor performance ${ }^{[1-5]}$. At normal dietary concentrations its neurostimulant effect is by antagonizing adenosine receptors ${ }^{[6-7]}$. Regular caffeine intake has been shown to decrease stimulant effect of an acute dose of caffeine ${ }^{[8-9]}$. Alternatively, it is also shown that an acute dose of caffeine has positive effect on performance in regular caffeine users and some also have reported a dose dependent relationship ${ }^{[10-13]}$. So the present study intends to see whether an acute dose of caffeine improves alertness and performance when administered to regular moderate caffeine users. This will help to answer the question of majority of daily caffeine consumers, are there benefits of drinking more than average daily dose of caffeine?

Simple reaction time is an important parameter to judge the alertness and visual motor performance as it represents the integrity of sensory, motor and coordination system of the body ${ }^{[14]}$. So, present study is carried out to see the reaction time in healthy young subjects who were not regular caffeine consumers, before and after acute dose of caffeine and in same subjects after six months of regular moderate caffeine consumption.

\section{Aim And Objectives}

1. To find out reaction time in 30 male and 30 female non caffeine consumer subjects before and after acute dose of caffeine.

2. To find out reaction time in same subjects before and after acute dose of caffeine, after six months of regular moderate caffeine consumption. 
3. To see the effect of acute dose of caffeine on reaction time in non-consumer subjects.

4. To see the effect of acute dose of caffeine on reaction time in same subjects after six months of regular moderate consumption of caffeine.

\section{Material And Method}

Thirty male and 30 female healthy subjects in age group 20 to 25 years were recruited for the study. Written informed consent was taken from each subject. Thorough general and systemic examination was carried out. Subjects having any major illness like or on treatment for hypertension, diabetes, kidney disease, depression, any major auditory or visual defect including colour blindness, consuming alcohol or tobacco were excluded from the study. Prior caffeine habits were taken in to consideration. Subjects were accepted only if they reported a caffeine intake equal to less than two servings i.e. $200 \mathrm{mg}$. In addition, all subjects were instructed to abstain from all caffeinated products for at least 24 hours prior to a scheduled test session.

All subjects were thoroughly acquainted with the operation of the apparatus. Before conducting the actual tests 10 practical sessions were given to each subject maintaining the experimental conditions with regards to the time and place of the test. Emphasis was laid on accuracy of response to minimize the error rate. Four practice trials were given each time before reading is taken.

One cup of coffee containing approximately $250 \mathrm{mg}$ of caffeine per cup was provided. Test was initiated half an hour after coffee consumption as it has been reported that peak levels may be obtained within 30 minutes after consumption ${ }^{[15]}$. The subjects were assessed as mentioned above, before and 30 minutes after intake of caffeine.

The same subjects were asked to drink 2-5 cups of coffee per day for next six months. Daily caffeine consumption was recorded prospectively for six months using caffeine diary in which participants documented the quantity and type of caffeinated items consumed. Caffeine intake was found out by using standard caffeine content values ${ }^{[16]}$. Subjects who consumed $200-600 \mathrm{mg} / \mathrm{day}$ of coffee were included. After six months, subjects were assessed before and 30 minutes after intake of caffeine. Subjects were told to consume caffeine like they normally do on the day of assessment. The assessment was done between 8 to $10 \mathrm{hrs}$ of normal caffeine consumption to avid additive or withdrawal effects. Because caffeine has a half-life of 6 to 8 hrs and withdrawal symptoms typically begin following overnight abstinence and peak between 20 to 51 hrs. ${ }^{[17-18]}$

Recording of reaction time: ${ }^{[5]}$ Reaction time was measured by a simple machine, "Responseanalyser", by INCO, YantraShilpa system, Pune. This machine provides audio (low and high pitched) and visual (red, green and yellow colours) stimuli. The response is given by pressing a soft touch key with a thumb of dominant hand. It provides display range of $9.999 \mathrm{sec}$ with an accuracy of 1 millisecond. The reaction time was recorded in an isolated, adequately illuminated, noise free room between 4-6 pm. It was ensured that the location and direction of instrument as well as the subject is constant, so also the distance between them. The reaction time is measured as follows:

1. A ready signal was given to the subject.

2. Subject was asked to press the button with thumb of dominant hand as soon as he/she receives the stimulus.

3. Reaction time was displayed in milliseconds.

4. Five readings were taken for each stimulus by randomly varying the foreperiod (range $0-10 \mathrm{sec}$ )

5 . The mean of the above readings was taken as reaction time for that stimulus.

The subjects were assessed as mentioned above, before and 30 minutes after intake of caffeine.

The experiment protocol was approved by the Research and Human Ethics Committee of G M C Miraj, Maharashtra, India.

\section{Statistical analysis}

Student's Paired $t$ test was applied to compare the RT before and after intake of caffeine. Unpaired $t$ test was applied to compare the audio-visual RT between male and female subjects. A P value $<0.05$ is considered as significant.

\section{Results}

Table 1: Reaction time in males before $\& 30 \mathrm{~min}$ after consumption of caffeine in non-caffeinated state.

\begin{tabular}{|l|l|l|l|l|}
\hline & $\begin{array}{l}\text { Before } \\
\text { Mean +- SD }\end{array}$ & $\begin{array}{l}\text { After } \\
\text { Mean +- SD }\end{array}$ & t-Value & P-Value \\
\hline VRT-R & $210.50+-3.27$ & $202.80+-3.02$ & $2.77366 \mathrm{E}-32$ & $<0.01$ \\
\hline VRT-G & $220.20+-1.71$ & $213.16+-1.70$ & $3.29067 \mathrm{E}-27$ & $<0.01$ \\
\hline VRT-Y & $233.03+-1.97$ & $226.36+-2.04$ & $3.40441 \mathrm{E}-28$ & $<0.01$ \\
\hline ART-L & $199.30+-2.26$ & $191.30+-2.13$ & $7.38343 \mathrm{E}-34$ & $<0.001$ \\
\hline ART-H & $194.63+-1.73$ & $184.43+-1.97$ & $9.5339 \mathrm{E}-19$ & $<0.001$ \\
\hline
\end{tabular}


Table 1 show that, Visual \& Auditory reaction time decreases very significantly after intake of caffeine in males.

Table 2: Reaction time in females before \& 30 min after consumption of caffeine in non-caffeinated

\begin{tabular}{|l|l|l|l|l|}
\hline & $\begin{array}{l}\text { Before } \\
\text { Mean +-SD }\end{array}$ & $\begin{array}{l}\text { After } \\
\text { Mean +- SD }\end{array}$ & t-Value & P-Value \\
\hline VRT-R & $216.50+-2.87$ & $208.30+-2.06$ & $5.85915 \mathrm{E}-25$ & $<0.001$ \\
\hline VRT-G & $227.10+-2.84$ & $221.16+-2.63$ & $4.88915 \mathrm{E}-17$ & $<0.001$ \\
\hline VRT-Y & $236.46+-3.15$ & $228.36+-3.20$ & $4.9865 \mathrm{E}-36$ & $<0.001$ \\
\hline ART-L & $204.50+-2.87$ & $197.00+-2.76$ & $5.39879 \mathrm{E}-36$ & $<0.001$ \\
\hline ART-H & $200.60+-3.02$ & $191.50+-3.00$ & $6.60006 \mathrm{E}-53$ & $<0.001$ \\
\hline
\end{tabular}

Table 2 show that, Visual \& Auditory reaction time decreases very significantly after intake of caffeine in females.

Table 3: Comparison of Reaction time in males \& females before consumption of caffeine.

\begin{tabular}{|l|l|l|l|l|}
\hline & $\begin{array}{l}\text { Male } \\
\text { Mean +- SD }\end{array}$ & $\begin{array}{l}\text { Female } \\
\text { Mean +- SD }\end{array}$ & t-Value & P-Value \\
\hline VRT-R & $210.50+-3.27$ & $216.50+-2.87$ & 0.295252666 & $>0.05$ \\
\hline VRT-G & $220.20+-1.71$ & $227.10+-2.84$ & 0.27677419 & $>0.05$ \\
\hline VRT-Y & $233.03+-1.97$ & $236.46+-3.15$ & 0.374645264 & $>0.05$ \\
\hline ART-L & $199.30+-2.26$ & $204.50+-2.87$ & 0.308589247 & $>0.05$ \\
\hline ART-H & $194.63+-1.73$ & $200.60+-3.02$ & 0.258869442 & $>0.05$ \\
\hline
\end{tabular}

Table 4: Comparison of Reaction time in males \& females 30 min after consumption of caffeine in

\begin{tabular}{|l|l|l|l|l|}
\hline \multicolumn{5}{|l|}{ non-caffeinated state. } \\
& $\begin{array}{l}\text { Male } \\
\text { Mean +- SD }\end{array}$ & $\begin{array}{l}\text { Female } \\
\text { Mean +- SD }\end{array}$ & t-Value & P-Value \\
\hline VRT-R & $202.80+-3.02$ & $208.30+-2.06$ & 0.311165763 & $>0.05$ \\
\hline VRT-G & $213.16+-1.70$ & $221.16+-2.63$ & 0.233765381 & $>0.05$ \\
\hline VRT-Y & $226.36+-2.04$ & $228.36+-3.20$ & 0.416840557 & $>0.05$ \\
\hline ART-L & $191.30+-2.13$ & $197.00+-2.76$ & 0.280936565 & $>0.05$ \\
\hline ART-H & $184.43+-1.97$ & $191.50+-3.00$ & 0.219780633 & $>0.05$ \\
\hline
\end{tabular}

Table $3 \& 4$ show that, males react faster than females though the results are not statistically significant.

Table 5: Reaction time in males before $\& 30$ min after consumption of caffeine after 6 months of regular moderate caffeine intake.

\begin{tabular}{|l|l|l|l|l|}
\hline & $\begin{array}{l}\text { Before } \\
\text { Mean +- SD }\end{array}$ & $\begin{array}{l}\text { After } \\
\text { Mean +- SD }\end{array}$ & t-Value & P-Value \\
\hline VRT-R & $203.03+-1.84$ & $197.16+-2.10$ & $2.23637 \mathrm{E}-26$ & $<0.05$ \\
\hline VRT-G & $213.03+-1.95$ & $207.16+-2.16$ & $2.23637 \mathrm{E}-26$ & $<0.05$ \\
\hline VR-Y & $225.73+-1.68$ & $220.46+-1.92$ & $2.13215 \mathrm{E}-24$ & $<0.05$ \\
\hline ART-L & $190.03+-1.97$ & $184.33+-1.80$ & $2.29303 \mathrm{E}-26$ & $<0.05$ \\
\hline ART-H & $188.50+-1.71$ & $182.66+-1.86$ & $2.58353 \mathrm{E}-32$ & $<0.02$ \\
\hline
\end{tabular}

Table 6: Reaction time in females before $\& 30$ min after consumption of caffeine after 6 months of regular moderate caffeine intake.

\begin{tabular}{|c|c|c|c|c|}
\hline & $\begin{array}{c}\text { Before } \\
\text { Mean +- SD }\end{array}$ & $\begin{array}{c}\text { After } \\
\text { Mean +- SD }\end{array}$ & t-Value & P-Value \\
\hline $\begin{array}{c}\text { VRT - } \\
\text { R }\end{array}$ & $211.80+-1.68$ & $205.96+-2.10$ & $2.44408 \mathrm{E}-27$ & $<0.05$ \\
\hline VRT-G & $223.00+-2.11$ & $217.00+-2.01$ & $2.11425 \mathrm{E}-31$ & $<0.05$ \\
\hline VRT-Y & $232.26+-2.54$ & $226.06+-2.70$ & $2.28787 \mathrm{E}-29$ & $<0.05$ \\
\hline ART-L & $198.80+-2.72$ & $192.86+-2.96$ & $2.17878 \mathrm{E}-28$ & $<0.05$ \\
\hline ART-H & $196.93+-3.40$ & $190.80+-3.45$ & $2.49605 \mathrm{E}-51$ & $<0.02$ \\
\hline
\end{tabular}

Table 5 \& 6 show that the Visual as well as Auditory reaction time decreases significantly after acute dose of caffeine in habitual caffeine consumers as well.Though the decrease is less than when recorded in nonhabitual state.

\section{Discussion}


We evaluated the effect of an acute moderate dose of caffeine on audio visual reaction time in non caffeine consumers and in same subjects after six months of regular moderate caffeine intake. The dose of 250 mg was used because it is proposed that, Caffeine particularly has a profound effect on the central nervous system. Caffeine produces more rapid, clearer flow of thought, allays drowsiness and fatigue, and increases the capability of a greater sustained intellectual effort and more perfect association of ideas. It also causes a keener appreciation of sensory stimuli and reaction time is diminished. All this occurs at doses of 150-250 mg of caffeine. ${ }^{[19]}$

In our study, the average values of the Visual and Auditory reaction times in both the sexes are slightly higher than the standard values. Further, the auditory reaction times are faster than visual reaction times. Compared with the ear, the eye takes longer time to get its message started along the nerve to the brain. This probably accounts for the difference in the auditory and visual Reaction Times ${ }^{[20]}$.

Also, males reacted faster than females though our result is not statistically significant. Similar results were found in the studies conducted by Jack Botwinick and Larry ${ }^{[21]}$, Baker BL and Thomas $\mathrm{A}^{[22]}$ as well as Dixit TB, Amin MG and Pathak JD ${ }^{[23]}$.

Visual Reaction Time to Red light is faster as compared to Green and Yellow light in both the sexes. Same results were found by Shenvi\&Balasubramanian in 1994. This can be explained on the basis of the Trichromatic theory of colour vision. In study conducted by Tomita \& co-workers using microelectrode penetration of a single cone, it is found that $74 \%$ of units peaked in the Red spectrum, $16 \%$ in the Blue spectrum \&only $10 \%$ in the Green spectrum ${ }^{[24-26]}$. Cattell in 1887 found that Reaction time for Red and Green colour is almost similar whereas reaction time for yellow colour was more. ${ }^{[27-29]}$

In our study, we found that after 30 minutes of $250 \mathrm{mg}$ of caffeine consumption the Reaction Time to Auditory and Visual stimuli reduced very very significantly in both Males and Females in non habitual caffeine consumption state. Caffeine increased attention and vigilance by stimulating the CNS and also increases cortical arousal and perceptual sensitivity as has been reported by various studies. ${ }^{[30]}$

Caffeine does this by antagonizing adenosine receptors. Adenosine is a bi-product of cellular activity and the adenosine receptors play a role in producing feelings of tiredness and the need to sleep. Caffeine's ability to block these receptors leads to higher levels of the body's natural stimulants, dopamine and norepinephrine. There are four known adenosine receptors. Out of these A1 and A2 are the two subtypes that caffeine (theoretically) antagonizes. Adenosine A1 receptors are presynaptic and reside in many areas of brain including the cerebral cortex and hippocampus where they inhibit the release of dopamine, glutamate and acetylcholine. ${ }^{[31]}$ Study showing the effect of caffeine on energetic arousal found that caffeinated beverages stimulate autonomic nervous system and increase alertness. ${ }^{[32]}$

We also found that, the Visual as well as Auditory reaction time decreases significantly after acute dose of caffeine in same subjects after regular long term consumption of moderate caffeine as well, though the decrease is less than that in non-habitual state. It may be because of development of tolerance and tolerance may have partially developed and was not overcome by the amount of caffeine administered. There may be another explanation that there may be physiological boundaries like, if the subject is already responding at higher speed then reduction in the reaction time will obviously be less. ${ }^{[33]}$

Although we got these results, we recognize that we should estimate our results carefully, because of some limitations. 1) Actual blood level of caffeine was not tested. 2) Effect of regular long term consumption of only moderate dose of caffeine on reaction time was assessed and low and high doses were not assessed.

\section{Conclusion}

We compared the effect of moderate acute dose of caffeine in non-habitual caffeine consumption state and in the same subjects after regular long term consumption of moderate caffeine to see whether the caffeine can produce stimulant effect beyond normal baseline. Our results suggest that caffeine was effective in improving audio-visual reaction time in both the states. This explains why daily caffeine users tend to consume more caffeine before challenging mental activity and we may say that, "Yes, that extra cup of coffee can boost your performance".

\section{References}

[1]. Fine BJ, Kobrick JL, Lieberman HR, Marlowe B, Riley RH, Tharion WJ. Effects of caffeine or diphenhydramine on visual vigilance. Psychopharmacology 1994; 114:233-238. [PubMed: 7838913]

[2]. Warburton DM. Effects of caffeine on cognition and mood without caffeine abstinence. Psychopharmacology (Berl) 1995; 119:6670. [PubMed: 7675951]

[3]. Robelin M, Rogers PJ. Mood and psychomotor performance effects of the first, but not of subsequent, cup-of-coffee equivalent doses of caffeine consumed after overnight caffeine abstinence. BehavPharmacol 1998; 9:611-618. [PubMed: 9862086]

[4]. Haskell CF, Kennedy DO, Wesnes KA, Scholey AB. Cognitive and mood improvements of caffeine in habitual consumers and habitual non-consumers of caffeine. Psychopharmacology 2005; 179:813-825. [PubMed: 15678363]

[5]. Pagar AB, Raut SE, Effect of caffeine on alertness of young healthy adults, IOSR journal of Dental and Medical Sciences, 13(7), 2014, 14-16. 
[6]. Nehlig A. Are we dependent upon coffee and caffeine? A review on human and animal data. NeurosciBiobehav Rev 1999; 23:563576. [PubMed: 10073894]

[7]. Ferre S. An update on the mechanisms of the psychostimulant effects of caffeine. J Neurochem 2008; 105:1067-1079. [PubMed: 18088379]

[8]. Chou DT, Khan S, Forde J, Hirsh KR. Caffeine tolerance: behavioral, electrophysiological and neurochemical evidence. Life Sci 1985; 36:2347-2358. [PubMed: 2989634]

[9]. Finn IB, Holtzman SG. Tolerance to caffeine-induced stimulation of locomotor activity in rats. J PharmacolExpTher 1986; 238:542-546. [PubMed: 3735131]

[10]. Frewer LJ, Lader M. The effects of caffeine on two computerized tests of attention and vigilance. Hum Psychopharmacol 1991; 6:119-128.

[11]. Warburton DM, Bersellini E, Sweeney E. An evaluation of a caffeinated taurine drink on mood, memory and information processing in healthy volunteers without caffeine abstinence. Psychopharmacology 2001; 158:322-328. [PubMed: 11713623]

[12]. Christopher G, Sutherland D, Smith A. Effects of caffeine in non-withdrawn volunteers. Hum PsychopharmacolClinExp 2005; 20:47-53.

[13]. Smith A, Sutherland D, Christopher G. Effects of repeated doses of caffeine on mood and performance of alert and fatigued volunteers. J Psychopharmacology 2005;19:620-626.

[14]. Dixit, T. B, Amin, M. G and Pathak, J. D. Assessment of Mental Alertness after various Phenothiazines. Journal of Indian Medical Association, 1964; 42: 173-175.

[15]. Barraclough, M.S., and Beech, J.R. Effects of caffeine on functional asymmetry in aposner letter-recognition task. Pharmacology, Biochemistry and Behavior, 1995; 52:731-735.

[16]. Center for Science in the Public Interest; www.cspinet.org

[17]. Patwardhan RV, Desmond PV, Johnson RF, Schenker S. Impaired elimination of caffeine by oralcontraceptive steroids. J Lab Clin Med 1980; 95:603-608. [PubMed: 7359014]

[18]. Juliano LM, Griffiths RR. A critical review of caffeine withdrawal: empirical validation of symptoms and signs, incidence, severity, and associated features. Psychopharmacology (Berl) 2004; 176:1-29. [PubMed: 15448977]

[19]. Stephenson.P.E. Physiologic and psychotropic effects of caffeine on man. Journal.Am.Dietetic Association1977; $71: 240$.

[20]. Woodworth and Schlosberg-Distraction. Experimental Psychology, pp-84-90.

[21]. Jack Botwinick and Larry. Thompson. Components of Reaction Time in relation to Age and Sex. The Journal of Genetic Psychology, 1966; 108: 175-183.

[22]. Blaine L. Baker and Thomas A. Jones. Age and Sex parameters in psychomotor Learning. Perceptual and Motor skills, 1964; 19:935-945.

[23]. Dixit, T. B, Amin, M. G and Pathak, J. D. Assessment of Mental Alertness after various Phenothiazines. Journal of Indian Medical Association, 1964; 42: 173-175.

[24]. Best and Taylor Physiological Basis of Medical Practice. 11th Edition. Pp420-421.

[25]. Devalios R. L. Central mechanisms of color vision. Handbook of sensory Physiology vol. V11/3A: Central Visual Information, edited by R. Jung Heidelberg, FRG: Springer, 1973: 209-253.

[26]. Devalios. R. L. Color vision mechanisms in Monkey. Journal of General Physiology, 1960; 43:115-128.

[27]. Cattell, J.MCk Mind.1886; 11; 63-65:220-242,377-392,524-538.

[28]. Cattell, J.Mck Mind.1887; 2:68-74.

[29]. Cattell, J.Mck. Philos.studies.1888; 4:241-250.

[30]. Avram Goldstein, Sophiakaizer and Richard warren. Psychotropic effects of caffeine in man. Alertness, Psychomotor co-ordination and Mood. The Journal of Pharmacology and Experimental Therapeutics, 1965; 150(1): 146-151.

[31]. Hari Prasath K. et al. TEA“AN ADDICTION NOR A MEDICINE”- A REVIEW. International Journal of Pharmacy, 4(3), 2014, 150-152.

[32]. QuinlanP. T, LaneJ, Moore. I, AspenJ, RycroftJ. A, O'Brien D. C. The acute physiological and mood effects of tea and coffee: The role of Caffeine level. Pharmacology. BiochemicalBehaviour, 2000; 66(1): 19-28.

[33]. Merideth A. Addicott and Paul J. Laurienti A comparison of the effects of caffeine following abstinence and normal caffeine use Psychopharmacology (Berl). 2009 December; 207(3): 423-431. doi:10.1007/s00213-009-1668-3 